Published in final edited form as:

Dent Clin North Am. 2013 October ; 57(4): 611-630. doi:10.1016/j.cden.2013.07.003.

\title{
Mucous Membrane Pemphigoid
}

\author{
Hong-Hui Xu, MD, PhD ${ }^{a, b, c}$, Victoria P. Werth, MD ${ }^{b, c,{ }^{*}}$, Ernesta Parisi, DMD ${ }^{\mathrm{d}, \mathrm{e},{ }^{*}, \text { and Thomas }}$ \\ P. Sollecito, DMD, FDS, RCSEd ${ }^{f}$ \\ aDepartment of Dermatology, No.1 Hospital of China Medical University, Shenyang, China \\ bPhiladelphia VAMC, Philadelphia, PA \\ 'Department of Dermatology, School of Medicine, University of Pennsylvania, Philadelphia, USA \\ dPrivate Practice, Totowa, NJ \\ eDepartment of Diagnostic Sciences, NJ Dental School, UMDNJ, Newark, NJ, USA \\ fDepartment of Oral Medicine, University of Pennsylvania School of Dental Medicine
}

\section{Keywords}

cicatricial pemphigoid; mucous membrane; subepithelial autoimmune disease; oral; ocular

\section{INTRODUCTION}

Mucous membrane pemphigoid (MMP) is a heterogeneous group of chronic, autoimmune subepithelial blistering diseases which predominantly involves the mucous membranes and occasionally the skin. In vivo, it is characterized by linear deposition of $\operatorname{IgG}, \operatorname{IgA}$, or C3 along the epithelial basement membrane zone. ${ }^{1,2}$

Although the oral and ocular mucosae are the most common sites affected, the nasopharynx, esophagus, larynx and anogenital region may also be involved. This disorder results in mucosal and/or skin blistering, ulceration, and subsequent scarring. The disease severity and distribution is highly variable, from mild cases involving only the oral mucosa, to severe cases involving the ocular, genital and esophageal mucosa. Involvement of the larynx or esophagus can give rise to strictures, which may be life-threatening. Since the consequences of this disease can be severe and limited therapeutic options are available once scarring develops, early diagnosis of this disease is critical. ${ }^{3}$ However, as the disease is rare and the early presenting symptoms are non-specific, MMP is often unrecognized in the early inflammatory stage.

Other nomenclatures for MMP include cicatricial pemphigoid, oral pemphigoid, ocular cicatricial pemphigoid (OCP), ocular pemphigoid, and benign mucous membrane pemphigoid

\footnotetext{
*Corresponding author for proof and reprints: Victoria P. Werth, M.D. Department of Dermatology, Hospital of the University of Pennsylvania, 1430 Penn Tower, $34^{\text {th }}$ and Civic Center Blvd, Philadelphia, PA 19104, Tel: 215-823-4208, Fax: 215-823-5171, werth@mail.med.upenn.edu.

Conflict of interest: The authors have nothing to disclose.

Publisher's Disclaimer: This is a PDF file of an unedited manuscript that has been accepted for publication. As a service to our customers we are providing this early version of the manuscript. The manuscript will undergo copyediting, typesetting, and review of the resulting proof before it is published in its final citable form. Please note that during the production process errors may be discovered which could affect the content, and all legal disclaimers that apply to the journal pertain.
} 
Autoantibodies to one or several autoantigens in the mucosal or epithelial BMZ have been identified in MMP patients. ${ }^{4-10}$ The association of MMP with human leukocyte antigen (HLA) major histocompatibility class II HLA-DQB $1 * 0301$ has been demonstrated. ${ }^{11-13}$ The cause is usually unknown, but there are a few reports of MMP triggered by medications such as methyldopa, clonidine and D-penicillamine. ${ }^{14,15}$

\section{EPIDEMIOLOGY}

The true incidence of MMP is unclear. A recent study from the United Kingdom demonstrated that ocular MMP accounted for $61 \%$ of the cases of newly diagnosed cicatricial conjunctivitis and the incidence was calculated as 0.8 per million population. ${ }^{16}$ The incidence of MMP was estimated to be 1.3-2.0 per million per year in France and Germany. ${ }^{17,} 18$ MMP predominantly affects women more often than men with a male to female ratio of nearly 2:1. ${ }^{19}$ MMP mainly occurs in the elderly population, commonly observed between 60 and 80 years of age. ${ }^{20}$ Albeit rare, children may also be affected. Approximately 20 cases of childhood onset MMP have been reported, among whom the youngest one was 10 months old. ${ }^{21-23}$ There is no known racial or geographic predilection.

\section{PATHOGENESIS}

The pathogenesis of MMP is complex. MMP has been found to be heterogeneous with several different antigens implicated. The pathogenic relevance of autoantibodies in MMP has been demonstrated in vivo and in vitro.

Circulating IgG and/or IgA autoantibodies against components of the basement membrane zone found in MMP patients' serum indicate MMP is mediated by a humoral immune response. ${ }^{24,25}$ Loss of immunologic tolerance to structural proteins in the BMZ results in development of autoantibodies. By use of immunoblotting and immunoprecipitation techniques, a variety of autoantigens including the bullous pemphigoid antigen 1 (BPAg1) (a 230-kDa protein, BP230), the bullous pemphigoid antigen 2 (BPAg2) (a 180-kDa protein, BP180), 24,25 integrin subunits $\alpha 6 / \beta 4$, laminin-332 (also called epiligrin and laminin-5), laminin-6, and collagen type I have been identified (Table 1). BPAg1 is an intracellular protein, whereas BPAg2 and a6//34 integrins are transmembrane proteins. The most frequently targeted autoantigen in MMP is BPAg2. Laminin-5 is thought to be the major ligand between the transmembrane proteins and the anchoring filaments. ${ }^{26}$ Anchoring fibrils, composed of type VII collagen, are located deeper in the lamina densa (Fig. 1). These autoantigens are not exclusive to MMP. Autoantibodies to both BPAg1 and BPAg2 can be present in BP, although BPAg2 is more common, and autoantibodies to type VII collagen is also found in epidermolysis bullosa acquisita.

An antibody-induced complement-mediated process results in epithelial detachment. Passive transfer studies in newborn mice have shown that antibodies to BPAg2 induce subepidermal blisters by an inflammatory mechanism. ${ }^{27,28}$ This interaction triggers immunologic events that result in the expression of inflammatory mediators that induce migration of lymphocytes, eosinophils, neutrophils, and mast cells to the BMZ. The separation of epithelium from the underlying tissue within the BMZ results from either direct cytotoxic action or the effect of lysosomal proteolytic enzymes. ${ }^{29,30}$

Passive transfer studies of antibodies against laminin 5 induce non-inflammatory subepidermal blisters which indicate that anti-laminin $5 \mathrm{IgG}$ is pathogenic, although the mechanism is not clear. ${ }^{31,32}$ Anti-a6 antibody produced separation of epithelium from basement membrane. ${ }^{33}$ Fibroblasts also are activated secondary to the production of inflammatory cytokines, such as transforming growth factor beta (TGF- $\beta$ ), which is known to induce fibrosis. ${ }^{34}$ The collagen produced may lead to scarring. 
Several studies have shown a predominance of $\mathrm{CD}^{+} \mathrm{T}$ cell and Langerhans cell infiltrates in the conjunctiva of MMP patients, which indicated the involvement of cellular immunity in the pathogenesis of MMP. ${ }^{34,35}$ The presence of Th17 lymphocytes in conjunctival biopsies was significantly increased in patients with OCP. ${ }^{36}$

\section{CLINICAL PRESENTATION}

MMP can affect multiple mucosal sites, occasionally with skin involvement. It is a chronic, progressive condition that most frequently involves the oral mucosa ( $85 \%$ of patients), followed by ocular conjunctiva (65\%), nasal mucosa (20-40\%), skin (25-30\%), anogenital area and/or pharynx (20\%), larynx (5-15\%), and esophagus (5-15\%) (Fig. 2-4, Table 2). ${ }^{37,38}$ Lesions occurring at any site may heal with scarring.

There is a great variability in the presentation and severity among patients with both localized and extensive involvement. Localized disease can progress to extensive disease. Those who have the disease affecting only the oral mucosa and/or the skin with less tendency of scarring with minimal clinical significance are defined as "low-risk" MMP patients. On the contrary, "high-risk" patients are those who have disease occurring in any of the following sites: ocular, nasopharyngeal, esophageal, laryngeal, and genital mucosa. $1,39,40$ The high tendency of MMP to scar in these sites is associated with a poor prognosis in spite of medical treatment. The ocular involvement can result in blindness. Scarring of the laryngeal mucosa can result in sudden asphyxiation, scarring of the esophagus can influence food taking, and scarring of the anogenital mucosa can significantly affect the patients' daily activities.

An appropriate scoring system can be used to assess the activity and damage of MMP disease and evaluating management outcome. Although there are several ocular grading systems for the severity of MMP, including Foster, Mondino and Tauber, none of these systems is universally accepted. ${ }^{41-43}$ Reeves et al. recently reported a grading system for both oral and ocular involvement, and no correlation in severity was found between the oral and ocular disease. ${ }^{44}$

\section{DIAGNOSIS}

\section{Diagnostic criteria}

The first international consensus statement on MMP recommended the diagnostic criteria must be based on clinical presentation as well as the presence of certain immunopathologic features (Table 3$).{ }^{1}$

Oral lesions usually involve the palate and gingival areas, and also on labial, tongue, and buccal mucosa. The lesions manifest as erythema, erosions, pseudomembrane, and sometimes intact blisters. Frequently the gingival lesions are descriptively referred to as desquamative gingivitis, which can also be seen in lichen planus and pemphigus vulgaris. The common ocular lesions are conjunctival inflammation and erosions, fornices shortening, corneal neovascularization and scarring. Anogenital lesions present as blisters, erosions and scarring.

When a patient is suspected of having MMP, tissue samples should be taken for histopathologic evaluation. The diagnostic tissue biopsy technique is important as the epithelium in these cases tends to dislodge easily from the underlying connective tissue. Improperly handling tissue may render the specimen non-diagnostic.

Specifically, one specimen of lesional tissue, including intact epithelium, should be submitted in formalin for routine histopathologic analysis with hematoxylin and eosin 
staining. MMP typically demonstrates the subepithelial split with an inflammatory infiltrate of eosinophils, lymphocytes and neutrophils, similar to the changes seen in other forms of pemphigoid. A second specimen should be obtained from perilesional tissue or from a site adjacent to a new vesicle or bulla rather than from vesicle, erosion or ulceration for direct immunofluorescence (DIF) and submitted in a buffered hypertonic saline solution, Michele's solution. The latter may give a false-negative interpretation since there may be no significant linear staining of immunoglobulin at the BMZ because of the loss of immunoreactants in longstanding lesions. The DIF typically shows a continuous, linear deposition of $\operatorname{IgG}$ and/or C3, and sometimes IgA along the BMZ. To ensure consistency, the consensus statement makes specific recommendations for the procedure of taking biopsies to enhance positive results and avoid additional surgical injury.

Indirect immunofluorescence (IIF) is used to detect circulating autoantibodies in a patient's serum. IIF is performed on an epithelial substrate, such as monkey esophagus, rat bladder, human skin or human buccal mucosa. Early studies using conventional skin substrates failed to show the association between antibody titer and MMP activity, while Setterfield et al demonstrated that titers of circulating IgG and IgA autoantibodies determined by the IIF technique using mucosal substrates might be predictors of disease severity ${ }^{45}$ IIF performed on $1 \mathrm{~mol} / \mathrm{L}$ salt-split normal human skin substrate, which is separated at the site of the lamina lucida portion of the BMZ can improve the sensitivity. Autoantibodies to BPAg2 and integrin subunits $a 6 / \beta 4$ bind the epidermal side (upper lamina lucida), whereas, autoantibodies to epiligrin and type VII collagen bind to the dermal side on salt-split tissue (lower lamina lucida).

Although distinct subgroups of MMP have been identified by use of the advanced immunopathologic and immunochemical techniques, diagnosis should still be made on the basis of clinical presentation combined with pathologic, immunohistologic, and serum antibody analysis.

\section{Subgroups}

Some investigators attempted to subdivide MMP into four subgroups based on autoantigens and clinical features. For a listing of these groups, please refer to Table $4 .{ }^{46-48}$

\section{Diagnostic dilemmas}

Diagnosis of MMP is often delayed because of the non-specific presentations in the early stage or inconclusive biopsies.

DIF often is helpful for diagnosis of pemphigoid, but it does not distinguish MMP from other subepithelial blistering dermatosis (SEBDs) such as bullous pemphigoid (BP), epidermolysis bullosa acquisita (EBA), or bullous systemic lupus erythematosus (BSLE). Distinction between the SEBDs may be clarified by combining the clinical findings with other sophisticated immunopathologic tests, which are not routinely requested in clinical practice. Circulating antibodies in MMP are less common than in BP. It is difficult to distinguish MMP from BP solely by DIF and IIF since most patients with MMP and BP have $\mathrm{BPAg} 2$. More specific immunological procedures have demonstrated that autoantibodies produced by MMP patients bind to the C-terminal portion of the BPAG2 antigen, whereas antibodies produced by patients with BP bind to the NC16A domain of the same autoantigen. ${ }^{49}$ This finding suggests that the autoantibody response is epitope specific for an antigen. Furthermore, heterogeneous antigens have been identified in MMP. Since autoantibodies to epiligrin and type VII collagen bind to the dermal side on salt-split tissue, IIF cannot differentiate MMP from EB. 
MMP usually can be differentiated from other mucocutaneous diseases such as lichen planus, erythema multiforme and pemphigus vulgaris by routine histopathology. Neither routine histopathogy nor immunopathology can differentiate MMP from other subepithelial autoimmune diseases. The differential diagnosis must be made on the basis of combination of clinical and histopathological features (Table 5).

\section{MANAGEMENT}

\section{Management goals}

The outcome of MMP therapy is related to the involved sites and early treatment. Involvement of ocular esophageal, genital and laryngopharyngeal mucosa is typically associated with irreversible scarring. The scarring process may be prevented or retarded by early appropriate interventions. The primary goal in the treatment of MMP is to prevent the progression to blindness, strictures and airway obstruction, thus preserving function and preventing disability.

Large randomized controlled clinical trials in MMP are not available. Treatment should be individualized depending on the severity of disease, age, general health, medical history, and any contraindications to the use of systemic medications. Collaboration of multidisciplinary specialists involving oral medicine experts, dermatologists, ophthalmologists, otolaryngologists and gastroenterologists will improve patient outcomes.

\section{Pharmacologic Strategies}

The treatment of MMP patients depends on the disease severity and the involved sites. The "low-risk" patients, those with involvement of oral mucosa and/or skin, may be managed initially with topical therapies. In severe and recalcitrant patients, combination with systemic therapy is necessary. The "high-risk" patients need aggressive systemic therapy with topical treatment. Restoration of function in cases with disabilities is also warranted.

\section{Topical agents}

High-potency topical corticosteroids remain the mainstay of treatment. Typically prescribed agents include fluocinonide, clobetasol propionate and betamethasone dipropionate. Desquamative gingival lesions may be managed effectively with the application of gel based topical corticosteroids to the lesion. Application may be facilitated by the placement of a resilient vacuum-formed occlusive splint that covers the involved gingiva (Fig. 5).

Consideration should be given to systemic absorption when using topical steroids. Steroid absorption may be enhanced when using an occlusive tray or if large areas of desquamation are presents. Patients should be closely monitored and frequent dosing over an extended period of time should be avoided to reduce systemic absorption. The complication of topical steroid therapy includes secondary infection with candida. Therefore, concomitant antifungal prophylaxis may be necessary.

Intralesional corticosteroids are useful for treating recalcitrant lesions or as an adjunct to topical steroid delivery. Intralesional injections usually result in accelerated healing (Fig. 6). Multiple site injection should be performed to distribute the steroid throughout the lesion. For the oral cavity $0.1 \mathrm{cc} / \mathrm{cm}^{2}$ triamcinalone $10 \mathrm{mg} / \mathrm{ml}$ may be used with improved results.

In cases of MMP non-responsive to topical steroid therapy, consideration should be given to the use of tacrolimus. Tacrolimus is commonly used for prophylaxis in prevention of organ rejection in transplant patients. Another widespread use for tacrolimus has been in the treatment of various T-cell-mediated dermatoses including atopic dermatitis and psoriasis. There are many case reports and clinical trials of the successful use of tacrolimus in the 
treatment of oral lichen planus, pemphigus vulgaris, and chronic graft versus host disease. Although reports of successful therapy of MMP with topical tacrolimus are limited, it has been shown to be effective in some cases of recalcitrant MMP involving oral mucosa, skin, and the conjunctiva. ${ }^{50-52}$

In patients susceptible to side effects and complications associated with systemic immunosuppression, topical tacrolimus is a useful alternative with good efficacy and safety. Palliative care for these patients should be considered with topical anesthetics, such as lidocaine or benzocaine, which can alleviate mouth pain, improve the patients' ability to swallow food and perform oral hygiene.

\section{Systemic medications}

When topical or intralesional therapies prove ineffective, or if there is involvement of the eyes, throat, or esophagus ("high-risk" patients), systemic medications are mandatory. Various systemic anti-inflammatory medications have been proposed as effective treatment for MMP (Table 6).

Dapsone-Studies have reported the effectiveness of dapsone in treating MMP. ${ }^{53-55}$ Dapsone is usually started at $50 \mathrm{mg} /$ day. The patient's hemoglobin should be evaluated after the first week of therapy and again one week after each increase in the dapsone dose. If there is no significant development of anemia and a negative review of systems for questions pertaining to symptoms of anemia (such as shortness of breath, fatigue and palpitations) as methemoglobin will not result in significant quantitative lowering of hemoglobin levels, dapsone should be increased slowly by $25 \mathrm{mg}$ every 7 days. A patient may need to maintain a certain dosage of dapsone for weeks before increasing to allow stabilization of the patient's hemoglobin. If hemoglobin drops more than $2 \mathrm{gm} / \mathrm{dl}$ or to below $10 \mathrm{gm} / \mathrm{dl}$, then the dose should not be increased further. The usual effective dose is between $100 \mathrm{mg}$ and 200 $\mathrm{mg} /$ day. ${ }^{56}$

Since dapsone therapy may have significant side effects, patients must be closely monitored while using this medication. These include hemolysis and methemoglobinemia. Glucose-6phosphate dehydrogenase (G6PD) is a metabolic enzyme involved in the red blood cell metabolism. Individuals who are G6PD deficient are at higher risk for developing extensive hemolysis. Before therapy is initiated, patients should be screened for G6PD deficiency. Dapsone hypersensitivity syndrome is another potential complication, which is characterized by fever, lymphadenopathy, hepatic damage, and generalized erythematous pustules. This syndrome usually presents during the first 4 to 5 weeks of dapsone therapy. Periodic monitoring of hemoglobin and liver function is essential while using dapsone to manage MMP. Adverse side effects may be reduced by the use of cimetidine and vitamin E. ${ }^{54,57,58}$

Corticosteroids-Systemic corticosteroids have a rapid onset of action. If steroids are used, the dose of corticosteroids should be tapered as other therapies become effective. Adjuvant therapy with corticosteroid-sparing agents contributes to halting the progression and corticosteroids tapering. Long-term use can cause a variety of side effects, including hyperglycemia, hypertension, hyperlipidemia, osteoporosis, gastric ulcers, secondary infection, and alterations of mood or even psychosis. Side effects can be minimized by careful monitoring and use of preventive strategies. ${ }^{59}$ The duration of glucocorticoid therapy and the glucocorticoid dose should be as low as possible. Purified protein derivatives tuberculin skin test or quantiferon gold testing for tuberculosis should be performed. Routine prophylaxis for ulcers usually is not needed, but it is necessary if the patient has a history of ulcers. Calcium and vitamin D supplementation is the most appropriate initial strategy to prevent bone loss in all patients. Bisphosphonates are a class of drugs that are approved by 
the FDA for preventing and treating glucocorticoid-induced osteoporosis. It is crucial to administer calcium and monitor bone density and consider the use oral bisphosphonates as indicated by guidelines. ${ }^{60}$

Cyclophosphamide (CYC)—Cyclophosphamide (CYC) exerts immunosuppressive effect by reducing the number of lymphocytes and reducing antibody production. CYC with or without corticosteroids has rapid efficacy in patients with severe refractory MMP. ${ }^{61-63}$ International consensus recommended CYC combined with corticosteroids as first-line treatment of "high-risk" patients. ${ }^{1}$ The total dose of CYC should be determined according to the disease progression and the degree of adverse effects experienced by patients.

Azathioprine (AZA) - AZA is usually used as an adjuvant therapy to corticosteroids. The maximum effect of AZA occurs after 8-12 weeks, while corticosteroids can suppress the inflammation more rapidly. Before the treatment, patients should be screened for thiopurine methyltransferase (TPMT). TPMT-deficient patients are prone to develop myelosuppression.

Mycophenolate mofetil (MMF)—MMF has been used to treat autoimmune blistering skin diseases. A marked improved effect with the combination of MMF with corticosteroids in the treatment of MMP has been reported. ${ }^{64-66}$ Staines et al. reported that treatment of MMP with MMF in uncontrolled case series resulted in control of inflammation in the majority of patients with minimal side effects. ${ }^{64} \mathrm{MMF}$ may be an effective and safe therapeutic option in MMP.

Methotrexate (MTX)—Oral MTX is moderately effective for management of inflammatory activity and for corticosteroid-sparing goals. ${ }^{67,} 68$ Low-dose MTX monotherapy is recommended as a useful first-line treatment in the treatment of mild-tomoderate ocular cicatricial pemphigoid. ${ }^{69} \mathrm{MTX}$ was well tolerated by most patients.

Cyclosporine-There are only sporadic reports of cyclosporine in treatment of MMP. Cyclosporine, along with corticosteroids, was effective in controlling inflammation and accomplishing corticosteroid-sparing goals. ${ }^{70-72}$ However, Foster et al. reported cyclosporine was ineffective in controlling MMP. ${ }^{73}$

Biologics-Biologic agents have been shown to be effective for management of a wide variety of mucocutaneous diseases. ${ }^{74,75}$ There have been a few reports of successful use of TNFa inhibitors in MMP. ${ }^{76-82}$ Etanercept can be effective in controlling severe MMP cases in patients who fail conventional immunosuppressive agents, but controlled trials are absent. Etanercept can be considered as an off-label alternative treatment for patients with MMP who would require aggressive immunosuppressive regimens. ${ }^{76}$

The combination therapy of rituximab (RTX) and intravenous immunoglobulin was reported to arrest disease progression and prevent total blindness in patients with recalcitrant ocular cicatricial pemphigoid. ${ }^{83,84}$ RTX can have dramatic efficacy in patients with severe, refractory MMP. ${ }^{83}, 85-89$ RTX is a highly promising treatment option in MMP, but longterm follow-up after RTX therapy is lacking. The ability of RTX to influence the clinical course of MMP remains to be determined.

Tetracyclines (minocycline)-Minocycline, a tetracycline-type antibiotic, has also been reported in the treatment of MMP. ${ }^{90}$ Side effects include nausea, vomiting, dizziness, photosensitivity, and hyperpigmentation. Due to its potent anti-inflammatory and immunosuppressive actions, it is a safe alternative for MMP patients. 
There are several reports showing the combination therapy of tetracycline and nicotinamide was effective for MMP. ${ }^{91,92}$ Nicotinamide is a vitamin $B_{3}$ or niacin derivative, usually used at $500-2500 \mathrm{mg} /$ day. Side effects including hepatotoxicity, pruritus, and flushing have been reported at higher doses.

Intravenous immunoglobulin (IVIG)-IVIG has been shown to be effective as an adjuvant treatment for MMP. ${ }^{83,93}$ Intravenous high dose immunoglobulin is administered at $400 \mathrm{mg} / \mathrm{kg} / \mathrm{d}$ for 5 consecutive days every 4 weeks. IVIG exerts effects such as complement blockade, inhibition of B cells, clearance of autoantibodies through the Fc receptor, and altering T cell function. IVIG with RTX may control disease progression and prevent total blindness in patients with recalcitrant ocular cicatricial pemphigoid. ${ }^{83}$ Yeh et al. identified a significant decline in the antibody titers and subsequent clinical response in 13 patients with extensive MMP unresponsive to immunosuppressive therapy or with substantial side effects. ${ }^{24}$ IVIG as monotherapy led to complete resolution of the symptoms and the laryngeal lesions without any side-effects. ${ }^{94}$ Failure of IVIG to control MMP is also reported..$^{95}$

\section{Nonpharmacologic Strategies}

Surgical management-Surgical management is not a curable treatment for MMP, but may prevent severe complications such as blindness, airway stenosis, esophageal and anogenital stricture in some patients. ${ }^{96,97}$ Surgery may be necessary for restoring function and improving life quality. Ophthalmic surgical interventions include entropion surgery, tarsorrhaphy, corneal grafts, amniotic membrane transplantation and keratoplasty. The bestcorrected visual acuity was improved significantly at the 4th postoperative week, but this improvement later disappeared. ${ }^{98}$ However, surgical procedures may aggravate the disease. To avoid disease exacerbations, it is important to perform surgery when the disease is quiescent with immunosuppressive treatment.

Laser-Efficacy of laser in treatment of oral MMP has been reported. Low-level laser therapy has been shown a promising effect in healing the oral erosions. Yilmaz et al. treated a patient of MMP involving oral mucosa by low-level laser therapy as an adjunct to local corticosteroid, which resolved the oral lesions uneventfully. ${ }^{94}$ Cafaro et al. reported 3 patients with MMP confined to the mouth who were treated with low-level laser. Each patient underwent two laser sessions weekly, with a complete resolution in clinical signs in all the patients with a mean number of laser sessions of $9.66( \pm 9.45)$. No reported complications or therapy side effects were observed in any of the patients treated. ${ }^{99}$ Moore et al. used transcleral diode laser cyclophotocoagulation to control raised intraocular pressure in a patient with ocular cicatricial pemphigoid without causing an exacerbation of the condition. ${ }^{100}$

\section{Self-Management Strategies}

Meticulous oral hygiene and avoidance of trauma is extremely important to decrease the plaque-induced gingival inflammation in patients with gingival lesions and prevent infection. Patients with MMP should avoid alcohol in mouthwashes as it may exacerbate irritation of the oral tissue.

\section{Evaluation, Adjustment, Recurrence}

The response to treatment is different among MMP patients and the prognosis is unpredictable. Relapses and progression are common, especially in patients with oral, ocular, laryngeal, esophageal and genital involvement. The treatment should be individualized and adjusted according to the disease severity, sites involved and response to 
the prior treatment (Figure 7). Since MMP usually affects elderly people, the general condition of the patient and contraindications to the systemic medications should be considered.

\section{SUMMARY}

MMP is chronic and frequently associated with exacerbations and remissions of clinical signs and symptoms. Clinicians should use pathologic and immunonological techniques to help diagnose patients. Multidisciplinary collaboration is often necessary for the diagnosis and proper treatment of MMP. Systemic adjuvant immunosuppressive therapy is necessary for patients with progressive disease. In spite of the advances in available immunosuppressive medications and biologics, scarring is a significant complication in many cases. Surgical intervention is not curable, however, it may be necessary for restoring function and improving quality of life.

\section{Acknowledgments}

This material is supported by the National Institutes of Health, including NIH K24-AR 1802207 (Werth), by the Department of Veterans Affairs, Veteran Health Administration, Office of Research and Development, Biomedical Laboratory Research and Development and by Innovative Research Teams in Universities, Liaoning Bureau of Education (LT2012012).

\section{References}

1. Chan LS, Ahmed AR, Anhalt GJ, et al. The first international consensus on mucous membrane pemphigoid: definition, diagnostic criteria, pathogenic factors, medical treatment, and prognostic indicators. Arch Dermatol. 2002; 138:370-9. [PubMed: 11902988]

2. Schmidt E, Zillikens D. Pemphigoid diseases. Lancet. 2013; 381:320-32. [PubMed: 23237497]

3. Srikumaran D, Akpek EK. Mucous membrane pemphigoid: recent advances. Current opinion in ophthalmology. 2012; 23:523-7. [PubMed: 23047169]

4. Schmidt E, Skrobek C, Kromminga A, et al. Cicatricial pemphigoid: IgA and IgG autoantibodies target epitopes on both intra- and extracellular domains of bullous pemphigoid antigen 180 . $\mathrm{Br} \mathrm{J}$ Dermatol. 2001; 145:778-83. [PubMed: 11736901]

5. Bernard P, Prost C, Lecerf V, et al. Studies of cicatricial pemphigoid autoantibodies using direct immunoelectron microscopy and immunoblot analysis. J Invest Dermatol. 1990; 94:630-5. [PubMed: 2182720]

6. Calabresi V, Carrozzo M, Cozzani E, et al. Oral pemphigoid autoantibodies preferentially target BP180 ectodomain. Clin Immunol. 2007; 122:207-3. [PubMed: 17141573]

7. Domloge-Hultsch N, Gammon WR, Briggaman RA, et al. Epiligrin, the major human keratinocyte integrin ligand, is a target in both an acquired autoimmune and an inherited subepidermal blistering skin disease. J Clin Invest. 1992; 90:1628-33. [PubMed: 1401088]

8. Chan LS, Majmudar AA, Tran HH, et al. Laminin-6 and laminin-5 are recognized by autoantibodies in a subset of cicatricial pemphigoid. J Invest Dermatol. 1997; 108:848-53. [PubMed: 9182809]

9. Luke MC, Darling TN, Hsu R, et al. Mucosal morbidity in patients with epidermolysis bullosa acquisita. Arch Dermatol. 1999; 135:954-9. [PubMed: 10456345]

10. Tyagi S, Bhol K, Natarajan K, et al. Ocular cicatricial pemphigoid antigen: partial sequence and biochemical characterization. Proc Natl Acad Sci U S A. 1996; 93:14714-9. [PubMed: 8962120]

11. Ahmed AR, Foster S, Zaltas M, et al. Association of DQw7 (DQB1*0301) with ocular cicatricial pemphigoid. Proc Natl Acad Sci U S A. 1991; 88:11579-82. [PubMed: 1763074]

12. Chan LS, Hammerberg C, Cooper KD. Significantly increased occurrence of HLA-DQB $1 * 0301$ allele in patients with ocular cicatricial pemphigoid. J Invest Dermatol. 1997; 108:129-32. [PubMed: 9008223] 
13. Setterfield J, Theron J, Vaughan RW, et al. Mucous membrane pemphigoid: HLA-DQB $1 * 0301$ is associated with all clinical sites of involvement and may be linked to antibasement membrane IgG production. Br J Dermatol. 2001; 145:406-14. [PubMed: 11531829]

14. Van Joost T, Van't Veen AJ. Drug-induced cicatricial pemphigoid and acquired epidermolysis bullosa. Clin Dermatol. 1993; 11:521-7. [PubMed: 8124642]

15. Laskaris G, Satriano RA. Drug-induced blistering oral lesions. Clin Dermatol. 1993; 11:545-50. [PubMed: 8124645]

16. Radford CF, Rauz S, Williams GP, et al. Incidence, presenting features, and diagnosis of cicatrising conjunctivitis in the United Kingdom. Eye (Lond). 2012; 26:1199-208. [PubMed: 22722485]

17. Bernard P, Vaillant L, Labeille B, et al. Incidence and distribution of subepidermal autoimmune bullous skin diseases in three French regions. Bullous Diseases French Study Group. Arch Dermatol. 1995; 131:48-52. [PubMed: 7826096]

18. Bertram F, Brocker EB, Zillikens D, et al. Prospective analysis of the incidence of autoimmune bullous disorders in Lower Franconia, Germany. J Dtsch Dermatol Ges. 2009; 7:434-40. [PubMed: 19170813]

19. Woo, SBGM. Ulcerative, vesicular, and bullous lesions. In: Greenberg, MSGM.; Ship, JA., editors. Burket's Oral Medicine: Diagnosis and Treatment. 11. Hamilton: B.C. Decker Inc; 2008.

20. Cohen SJ, Pittelkow MR, Su WP. Cutaneous manifestations of cryoglobulinemia: clinical and histopathologic study of seventy-two patients. J Am Acad Dermatol. 1991; 25:21-7. [PubMed: 1880249]

21. Jolliffe DS, Sim-Davis D. Cicatricial pemphigoid in a young girl: report of a case. Clin Exp Dermatol. 1977; 2:281-4. [PubMed: 336250]

22. Rogers M, Painter D. Cicatricial pemphigoid in a four-year-old child: A case report. Australas J Dermatol. 1981; 22:21-3. [PubMed: 7020678]

23. Kharfi M, Khaled A, Anane R, et al. Early onset childhood cicatricial pemphigoid: a case report and review of the literature. Pediatr Dermatol. 2010; 27:119-24. [PubMed: 20537062]

24. Yeh SW, Usman AQ, Ahmed AR. Profile of autoantibody to basement membrane zone proteins in patients with mucous membrane pemphigoid: long-term follow up and influence of therapy. Clin Immunol. 2004; 112:268-72. [PubMed: 15308120]

25. Carrozzo M, Cozzani E, Broccoletti R, et al. Analysis of antigens targeted by circulating IgG and IgA antibodies in patients with mucous membrane pemphigoid predominantly affecting the oral cavity. J Periodontol. 2004; 75:1302-8. [PubMed: 15562906]

26. Yancey KB. Adhesion molecules. II: Interactions of keratinocytes with epidermal basement membrane. J Invest Dermatol. 1995; 104:1008-14. [PubMed: 7769251]

27. Liu Z, Zhou X, Shapiro SD, et al. The serpin alpha1-proteinase inhibitor is a critical substrate for gelatinase B/MMP-9 in vivo. Cell. 2000; 102:647-55. [PubMed: 11007483]

28. Nishie W, Sawamura D, Goto M, et al. Humanization of autoantigen. Nat Med. 2007; 13:378-83. [PubMed: 17322897]

29. Eversole LR. Immunopathology of oral mucosal ulcerative, desquamative, and bullous diseases. Selective review of the literature. Oral Surg Oral Med Oral Pathol. 1994; 77:555-71. [PubMed: 8065717]

30. Eversole LR. Adhesion molecules and oral mucosal diseases. Oral Dis. 1996; 2:185-7. [PubMed: 9081756]

31. Lazarova Z, Yee C, Darling T, et al. Passive transfer of anti-laminin 5 antibodies induces subepidermal blisters in neonatal mice. J Clin Invest. 1996; 98:1509-18. [PubMed: 8833897]

32. Lazarova Z, Hsu R, Yee C, et al. Human anti-laminin 5 autoantibodies induce subepidermal blisters in an experimental human skin graft model. J Invest Dermatol. 2000; 114:178-84. [PubMed: 10620135]

33. Bhol KC, Goss L, Kumari S, et al. Autoantibodies to human alpha6 integrin in patients with oral pemphigoid. J Dent Res. 2001; 80:1711-5. [PubMed: 11669480]

34. Bernauer W, Wright $P$, Dart JK, et al. The conjunctiva in acute and chronic mucous membrane pemphigoid. An immunohistochemical analysis. Ophthalmology. 1993; 100:339-46. [PubMed: 8460003] 
35. Bodaghi B, Bertin V, Paques M, et al. Limbal conjunctival Langerhans cell density in ocular cicatricial pemphigoid: an indirect immunofluorescence study on Dispase-split conjunctiva. Curr Eye Res. 1997; 16:820-4. [PubMed: 9255511]

36. Lambiase A, Micera A, Mantelli F, et al. T-helper 17 lymphocytes in ocular cicatricial pemphigoid. Mol Vis. 2009; 15:1449-55. [PubMed: 19641634]

37. Chan LS. Mucous membrane pemphigoid. Clin Dermatol. 2001; 19:703-11. [PubMed: 11705679]

38. Thorne JE, Anhalt GJ, Jabs DA. Mucous membrane pemphigoid and pseudopemphigoid. Ophthalmology. 2004; 111:45-52. [PubMed: 14711713]

39. Tauber J, Sainz de la Maza M, Foster CS. Systemic chemotherapy for ocular cicatricial pemphigoid. Cornea. 1991; 10:185-95. [PubMed: 2055022]

40. Kourosh AS, Yancey KB. Therapeutic approaches to patients with mucous membrane pemphigoid. Dermatol Clin. 2011; 29:637-41. [PubMed: 21925010]

41. Foster CS. Cicatricial pemphigoid. Trans Am Ophthalmol Soc. 1986; 84:527-663. [PubMed: 3296406]

42. Tauber J, Jabbur N, Foster CS. Improved detection of disease progression in ocular cicatricial pemphigoid. Cornea. 1992; 11:446-51. [PubMed: 1424674]

43. Williams GP, Saw VP, Saeed T, et al. Validation of a fornix depth measurer: a putative tool for the assessment of progressive cicatrising conjunctivitis. Br J Ophthalmol. 2011; 95:842-7. [PubMed: 20956276]

44. Reeves GM, Lloyd M, Rajlawat BP, et al. Ocular and oral grading of mucous membrane pemphigoid. Graefes Arch Clin Exp Ophthalmol. 2012; 250:611-8. [PubMed: 22081231]

45. Setterfield J, Shirlaw PJ, Kerr-Muir M, et al. Mucous membrane pemphigoid: a dual circulating antibody response with $\mathrm{IgG}$ and $\mathrm{IgA}$ signifies a more severe and persistent disease. Br J Dermatol. 1998; 138:602-10. [PubMed: 9640363]

46. Rashid KA, Gurcan HM, Ahmed AR. Antigen specificity in subsets of mucous membrane pemphigoid. J Invest Dermatol. 2006; 126:2631-6. [PubMed: 16810295]

47. Chan LS, Yancey KB, Hammerberg C, et al. Immune-mediated subepithelial blistering diseases of mucous membranes. Pure ocular cicatricial pemphigoid is a unique clinical and immunopathological entity distinct from bullous pemphigoid and other subsets identified by antigenic specificity of autoantibodies. Arch Dermatol. 1993; 129:448-55. [PubMed: 7682049]

48. Oyama N, Setterfield JF, Powell AM, et al. Bullous pemphigoid antigen II (BP180) and its soluble extracellular domains are major autoantigens in mucous membrane pemphigoid: the pathogenic relevance to HLA class II alleles and disease severity. Br J Dermatol. 2006; 154:90-8. [PubMed: 16403100]

49. Yancey KB, Egan CA. Pemphigoid: clinical, histologic, immunopathologic, and therapeutic considerations. JAMA. 2000; 284:350-6. [PubMed: 10891967]

50. Lee HY, Blazek C, Beltraminelli H, et al. Oral mucous membrane pemphigoid: complete response to topical tacrolimus. Acta Derm Venereol. 2011; 91:604-5. [PubMed: 21597668]

51. Suresh L, Martinez Calixto LE, Radfar L. Successful treatment of mucous membrane pemphigoid with tacrolimus. Spec Care Dentist. 2006; 26:66-70. [PubMed: 16681241]

52. Assmann T, Becker J, Ruzicka T, et al. Topical tacrolimus for oral cicatricial pemphigoid. Clin Exp Dermatol. 2004; 29:674-6. [PubMed: 15550151]

53. Arash A, Shirin L. The management of oral mucous membrane pemphigoid with dapsone and topical corticosteroid. J Oral Pathol Med. 2008; 37:341-4. [PubMed: 18331284]

54. Rogers RS 3rd, Mehregan DA. Dapsone therapy of cicatricial pemphigoid. Semin Dermatol. 1988; 7:201-5. [PubMed: 3153445]

55. Ciarrocca KN, Greenberg MS. A retrospective study of the management of oral mucous membrane pemphigoid with dapsone. Oral Surg Oral Med Oral Pathol Oral Radiol Endod. 1999; 88:159-63. [PubMed: 10468458]

56. Sollecito TP, Parisi E. Mucous membrane pemphigoid. Dental clinics of North America. 2005; 49:91-106. viii. [PubMed: 15567363]

57. Kelly JW, Scott J, Sandland M, et al. Vitamin E and dapsone-induced hemolysis. Arch Dermatol. 1984; 120:1582-4. [PubMed: 6508329] 
58. Rhodes LE, Tingle MD, Park BK, et al. Cimetidine improves the therapeutic/toxic ratio of dapsone in patients on chronic dapsone therapy. Br J Dermatol. 1995; 132:257-62. [PubMed: 7888363]

59. Moghadam-Kia S, Werth VP. Prevention and treatment of systemic glucocorticoid side effects. Int J Dermatol. 2010; 49:239-48. [PubMed: 20465658]

60. Pereira RM, Carvalho JF, Paula AP, et al. Guidelines for the prevention and treatment of glucocorticoid-induced osteoporosis. Rev Bras Reumatol. 2012; 52:580-93. [PubMed: 22885424]

61. Hayashi H, Sakai J, Matsuura H, et al. Cyclophosphamide and amniotic membrane transplantation in the management of ocular disease in a case of antiepiligrin cicatricial pemphigoid. Clin Exp Dermatol. 2009; 34:e477-9. [PubMed: 19747320]

62. Musette P, Pascal F, Hoang-Xuan T, et al. Treatment of cicatricial pemphigoid with pulse intravenous cyclophosphamide. Arch Dermatol. 2001; 137:101-2. [PubMed: 11176680]

63. Pandya AG, Warren KJ, Bergstresser PR. Cicatricial pemphigoid successfully treated with pulse intravenous cyclophosphamide. Arch Dermatol. 1997; 133:245-7. [PubMed: 9041848]

64. Staines K, Hampton PJ. Treatment of mucous membrane pemphigoid with the combination of mycophenolate mofetil, dapsone, and prednisolone: a case series. Oral Surg Oral Med Oral Pathol Oral Radiol. 2012; 114:e49-56. [PubMed: 22727107]

65. Doycheva D, Deuter C, Blumenstock G, et al. Long-term results of therapy with mycophenolate mofetil in ocular mucous membrane pemphigoid. Ocul Immunol Inflamm. 2011; 19:431-8. [PubMed: 22106912]

66. Rallis E, Anyfantakis V. Coexistent psoriasis and bullous pemphigoid responding to mycophenolate mofetil monotherapy. Skinmed. 2008; 7:101-2. [PubMed: 18327004]

67. Roufas A, Kim P, Reeves D, et al. A rare unilateral case of ocular mucous membrane pemphigoid. Cornea. 2010; 29:1462-4. [PubMed: 20847684]

68. Gangaputra S, Newcomb CW, Liesegang TL, et al. Methotrexate for ocular inflammatory diseases. Ophthalmology. 2009; 116:2188-98. e2181. [PubMed: 19748676]

69. McCluskey P, Chang JH, Singh R, et al. Methotrexate therapy for ocular cicatricial pemphigoid. Ophthalmology. 2004; 111:796-801. [PubMed: 15051215]

70. Alonso A, Bignone ML, Brunzini M, et al. Ocular autoimmune pemphigoid and cyclosporin A. Allergol Immunopathol (Madr). 2006; 34:113-5. [PubMed: 16750121]

71. Kacmaz RO, Kempen JH, Newcomb C, et al. Cyclosporine for ocular inflammatory diseases. Ophthalmology. 2010; 117:576-84. [PubMed: 20031223]

72. Williams DY, Oziemski M, Varigos G. Cyclosporine therapy of life-threatening cicatricial pemphigoid affecting the respiratory tract. Int J Dermatol. 1995; 34:639-41. [PubMed: 7591465]

73. Foster CS, Neumann R, Tauber J. Long-term results of systemic chemotherapy for ocular cicatricial pemphigoid. Doc Ophthalmol. 1992; 82:223-9. [PubMed: 1303858]

74. O'Neill ID, Scully C. Biologics in oral medicine: principles of use and practical considerations. Oral Dis. 2012; 18:525-36. [PubMed: 22420757]

75. O'Neill ID. Off-label use of biologicals in the management of inflammatory oral mucosal disease. J Oral Pathol Med. 2008; 37:575-81. [PubMed: 18764859]

76. Canizares MJ, Smith DI, Conners MS, et al. Successful treatment of mucous membrane pemphigoid with etanercept in 3 patients. Arch Dermatol. 2006; 142:1457-61. [PubMed: 17116836]

77. Cusano F, Iannazzone SS, Riccio G, et al. Coexisting bullous pemphigoid and psoriasis successfully treated with etanercept. Eur J Dermatol. 2010; 20:520. [PubMed: 20403800]

78. Kennedy JS, Devillez RL, Henning JS. Recalcitrant cicatricial pemphigoid treated with the antiTNF-alpha agent etanercept. J Drugs Dermatol. 2010; 9:68-70. [PubMed: 20120429]

79. Prey S, Robert PY, Drouet M, et al. Treatment of ocular cicatricial pemphigoid with the tumour necrosis factor alpha antagonist etanercept. Acta Derm Venereol. 2007; 87:74-5. [PubMed: 17225020]

80. Sacher C, Rubbert A, Konig C, et al. Treatment of recalcitrant cicatricial pemphigoid with the tumor necrosis factor alpha antagonist etanercept. J Am Acad Dermatol. 2002; 46:113-5. [PubMed: 11756956] 
81. Schulz S, Deuster D, Schmidt E, et al. Therapeutic effect of etanercept in anti-laminin 5 (laminin 332) mucous membrane pemphigoid. Int J Dermatol. 2011; 50:1129-31. [PubMed: 22126878]

82. Schultz HY, Diaz LA, Sirois DA, et al. Generating consensus research goals and treatment strategies for pemphigus and pemphigoid: The 2010 JC Bystryn Pemphigus and Pemphigoid Meeting. J Invest Dermatol. 2011; 131:1395-9. [PubMed: 21673705]

83. Foster CS, Chang PY, Ahmed AR. Combination of rituximab and intravenous immunoglobulin for recalcitrant ocular cicatricial pemphigoid: a preliminary report. Ophthalmology. 2010; 117:861-9. [PubMed: 20045562]

84. Shetty S, Ahmed AR. Critical analysis of the use of rituximab in mucous membrane pemphigoid: a review of the literature. J Am Acad Dermatol. 2013; 68:499-506. [PubMed: 23200198]

85. Le Roux-Villet C, Prost-Squarcioni C, Alexandre M, et al. Rituximab for patients with refractory mucous membrane pemphigoid. Arch Dermatol. 2011; 147:843-9. [PubMed: 21422323]

86. Ross AH, Jaycock P, Cook SD, et al. The use of rituximab in refractory mucous membrane pemphigoid with severe ocular involvement. Br J Ophthalmol. 2009; 93:421-2. 548. [PubMed: 19321473]

87. Hertl M, Bernard P, Borradori L. Rituximab for severe mucous membrane pemphigoid: safe enough to be drug of first choice? Arch Dermatol. 2011; 147:855-6. [PubMed: 21768487]

88. Kasperkiewicz M, Shimanovich I, Ludwig RJ, et al. Rituximab for treatment-refractory pemphigus and pemphigoid: a case series of 17 patients. J Am Acad Dermatol. 65:552-8. [PubMed: 21641080]

89. Schumann T, Schmidt E, Booken N, et al. Successful treatment of mucous membrane pemphigoid with the anti-CD-20 antibody rituximab. Acta Derm Venereol. 2009; 89:101-2. [PubMed: 19197558]

90. Poskitt L, Wojnarowska F. Minimizing cicatricial pemphigoid orodynia with minocycline. Br J Dermatol. 1995; 132:784-9. [PubMed: 7772486]

91. Reiche L, Wojnarowska F, Mallon E. Combination therapy with nicotinamide and tetracyclines for cicatricial pemphigoid: further support for its efficacy. Clin Exp Dermatol. 1998; 23:254-7. [PubMed: 10233619]

92. Sakamoto K, Mori K, Hashimoto T, et al. Antiepiligrin cicatricial pemphigoid of the larynx successfully treated with a combination of tetracycline and niacinamide. Arch Otolaryngol Head Neck Surg. 2002; 128:1420-3. [PubMed: 12479732]

93. Mignogna MD, Leuci S, Piscopo R, et al. Intravenous immunoglobulins and mucous membrane pemphigoid. Ophthalmology. 2008; 115:752-2. e751. [PubMed: 18387410]

94. Yilmaz HG, Kusakci-Seker B, Bayindir H, et al. Low-level laser therapy in the treatment of mucous membrane pemphigoid: a promising procedure. J Periodontol. 2010; 81:1226-30. [PubMed: 20450370]

95. Iaccheri B, Roque M, Fiore T, et al. Ocular cicatricial pemphigoid, keratomycosis, and intravenous immunoglobulin therapy. Cornea. 2004; 23:819-22. [PubMed: 15502484]

96. Trimarchi M, Bellini C, Fabiano B, et al. Multiple mucosal involvement in cicatricial pemphigoid. Acta Otorhinolaryngol Ital. 2009; 29:222-5. [PubMed: 20161882]

97. Higgins TS, Cohen JC, Sinacori JT. Laryngeal mucous membrane pemphigoid: a systematic review and pooled-data analysis. Laryngoscope. 2010; 120:529-36. [PubMed: 20058317]

98. Sotozono C, Inatomi T, Nakamura T, et al. Visual improvement after cultivated oral mucosal epithelial transplantation. Ophthalmology. 2013; 120:193-200. [PubMed: 23084239]

99. Cafaro A, Broccoletti R, Arduino PG. Low-level laser therapy for oral mucous membrane pemphigoid. Lasers Med Sci. 2012; 27:1247-50. [PubMed: 22706567]

100. Moore SP, Spiteri A, Booth A. Transscleral diode laser cyclophotocoagulation in a patient with ocular cicatricial pemphigoid. Ophthalmic Surg Lasers Imaging. 2009; 40:593-6. [PubMed: 19928727]

101. Ahmed AR, Hombal SM. Cicatricial pemphigoid. Int J Dermatol. 1986; 25:90-6. [PubMed: 3516897]

102. Kurzhals G, Stolz W, Maciejewski W, et al. Localized cicatricial pemphigoid of the BrunstingPerry type with transition into disseminated cicatricial pemphigoid. Report of a case proved by 
preembedding immunogold electron microscopy. Arch Dermatol. 1995; 131:580-5. [PubMed: 7741546]

103. Wolff K, Rappersberger K, Steiner A, et al. Vegetating cicatricial pemphigoid. A new subset of the cicatricial pemphigoid spectrum. Arch Dermatol Res. 1987; 279 (Suppl):S30-7. [PubMed: 3310921]

104. Das S, Blanco G, Ahmed A, et al. Cicatricial pemphigoid of the scalp mimicking discoid lupus erythematosus. J Am Acad Dermatol. 2011; 65:886-7. [PubMed: 21920254]

105. Messmer EM, Hintschich CR, Partscht K, et al. Ocular cicatricial pemphigoid. Retrospective analysis of risk factors and complications. Ophthalmologe. 2000; 97:113-20. [PubMed: 10734737] 


\section{KEY POINTS}

Mucous membrane pemphigoid is a heterogeneous subepithelial blistering disease that predominantly affects the mucous membranes, including the conjunctiva and occasionally the skin. Like other forms of pemphigoid, the disorder is characterized by the formation of autoantibodies against structural proteins of the dermal-epidermal junction. Early diagnosis is critical and immunosuppressive treatment may prevent scarring. 


\section{Hemidesmosome structure}

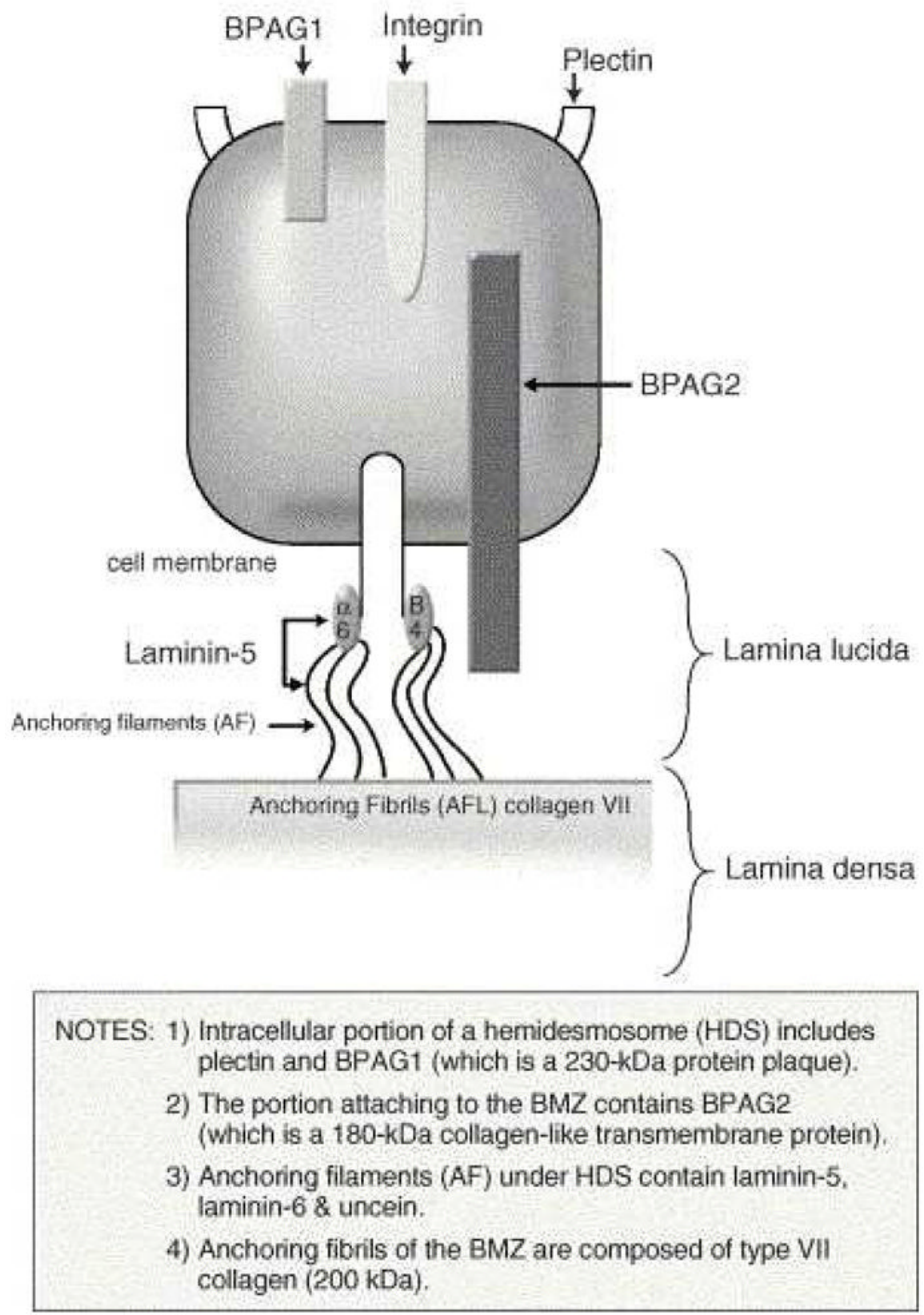

Fig. 1.

Components of the basement membrane zone. 


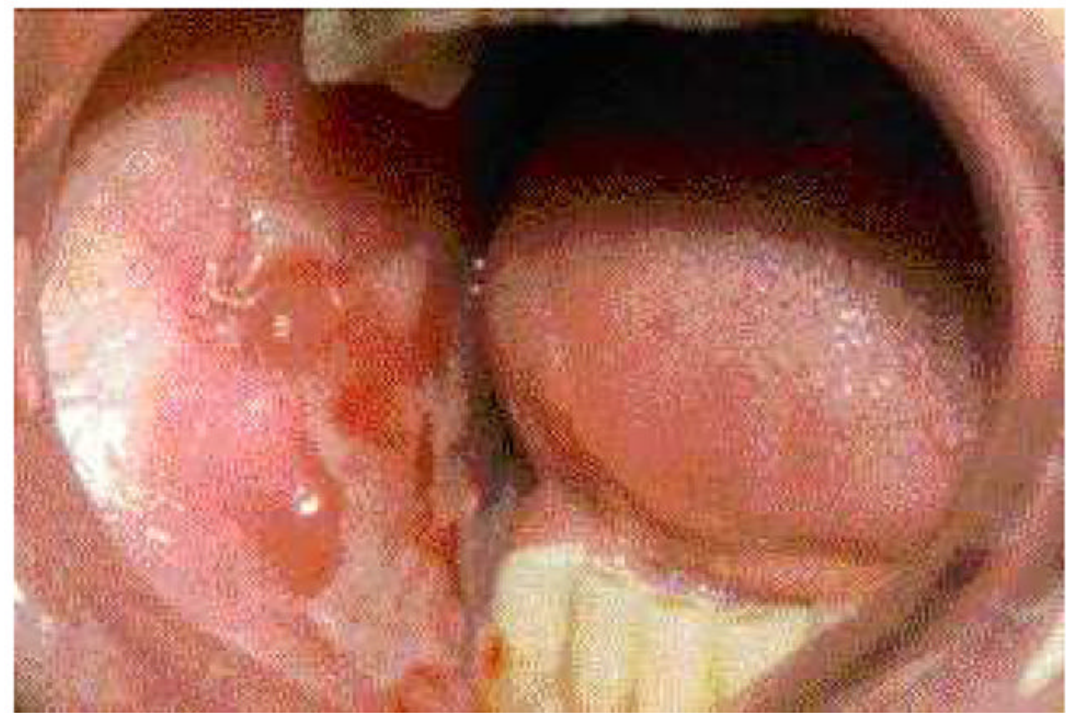

Fig. 2.

Ulceration and the scarring on the buccal mucosa of a patient with MMP. 


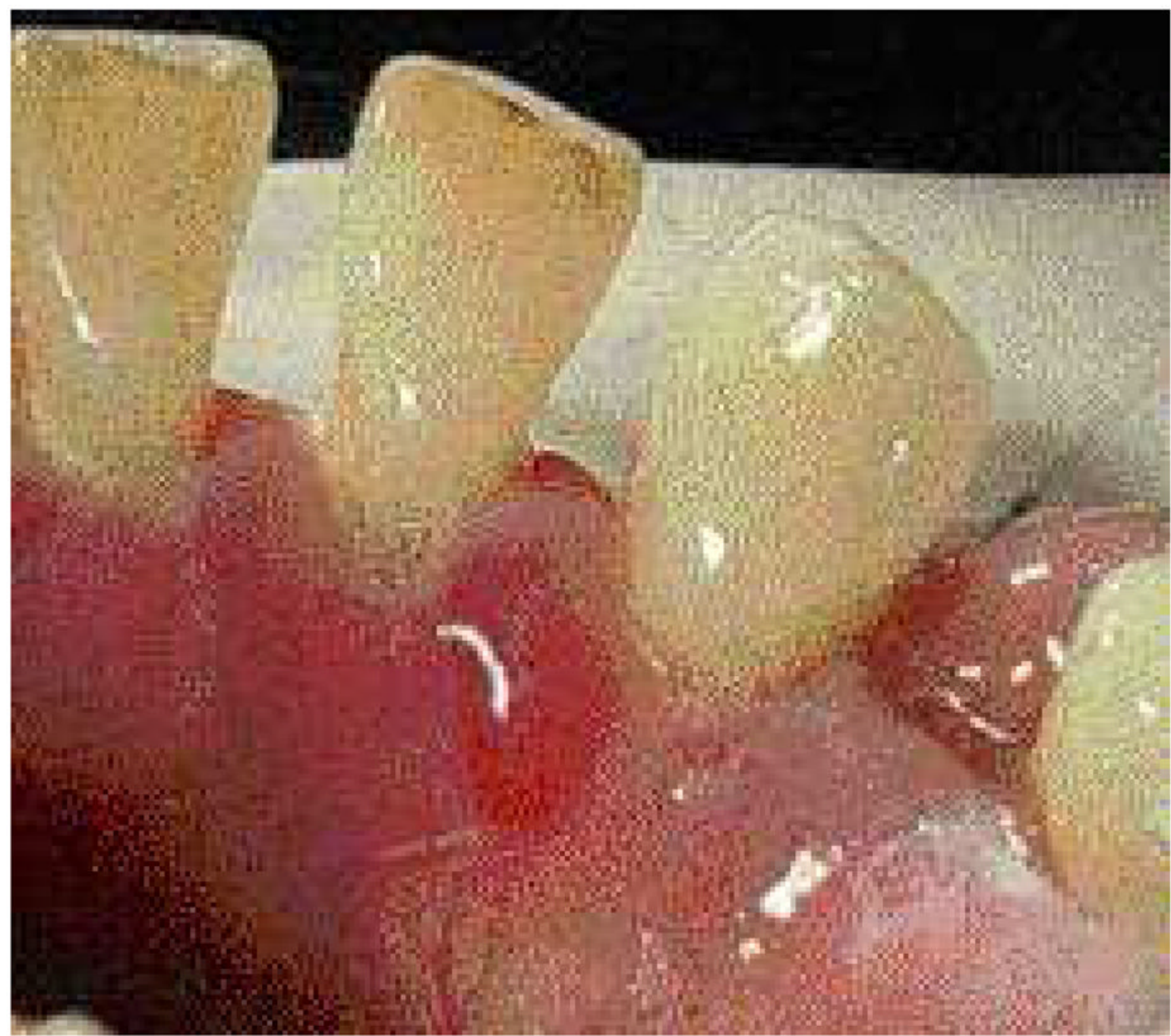

Fig. 3.

Intact blood-filled vesicle. 


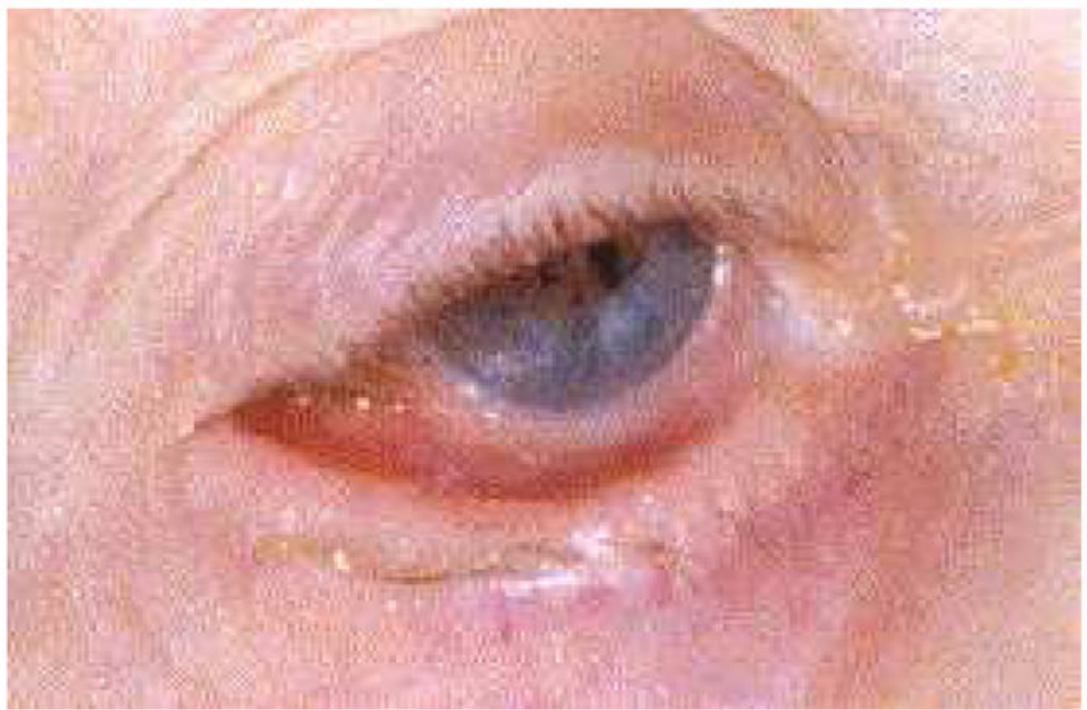

Fig. 4.

Symblepharon formation resulting from the scarring of the bulbar and palpebral conjunctiva 


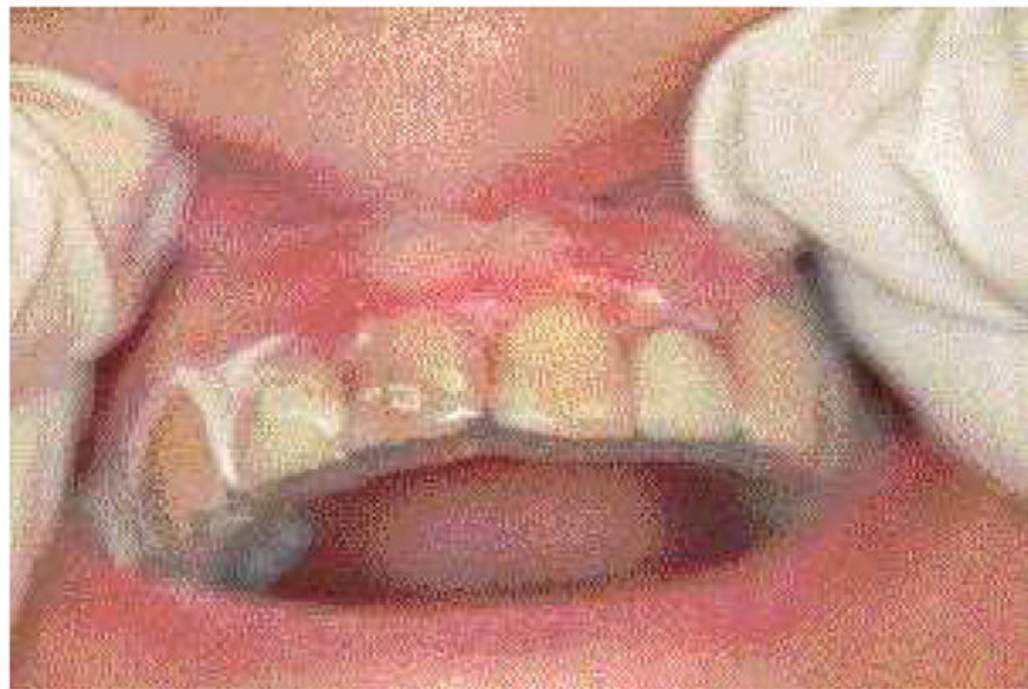

Fig. 5.

A resilient splint serving as an occlusive dressing over the attached gingiva. 


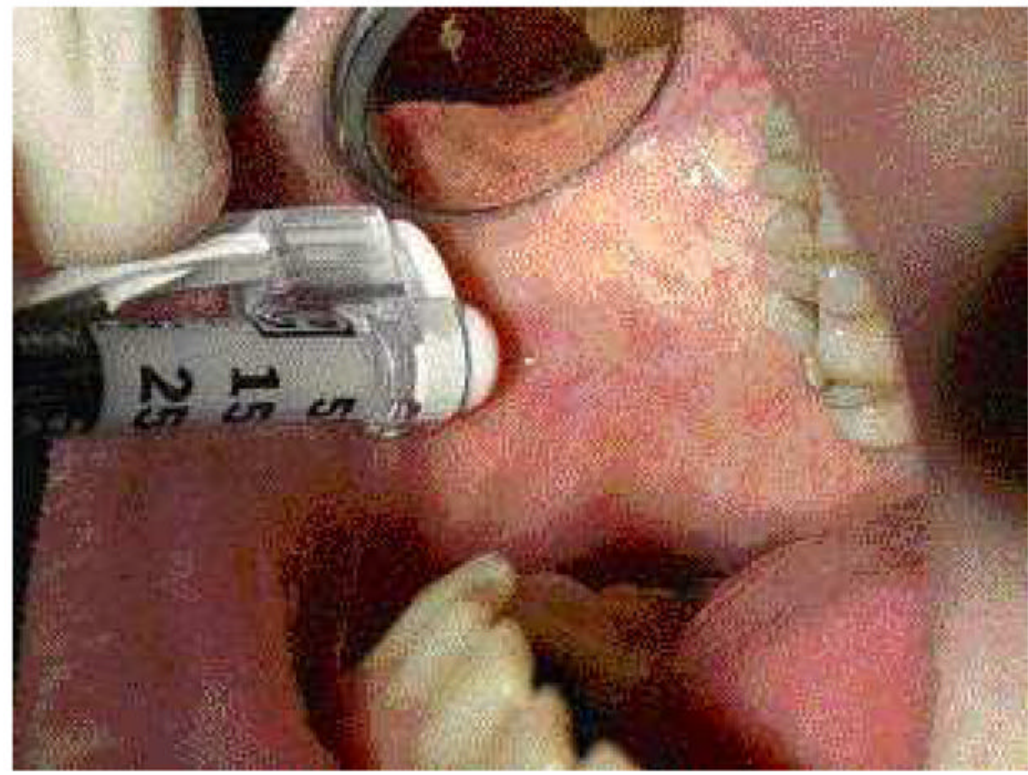

Fig. 6.

Intralesional injection of steroid preparation. 


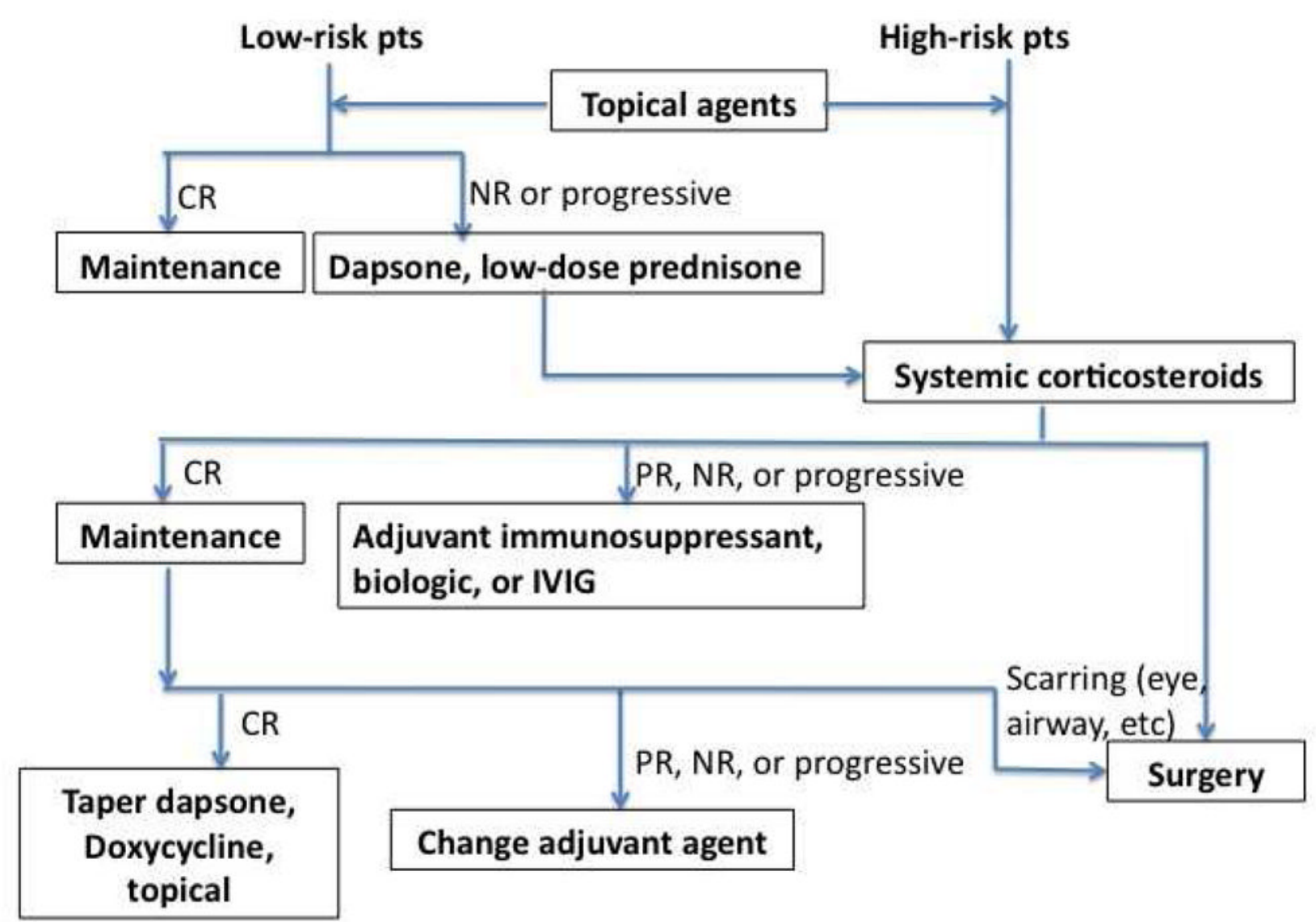

Fig. 7.

Treatment algorithm for MMP. CR, complete response; NR, no response; PR, partial response. 
Table 1

Autoantigens identified in MMP

\begin{tabular}{|ll|}
\hline Autoantigens & Location \\
\hline BPAg2 (BP180) & Hemidesmosome/Lamina lucida (transmembrane) \\
\hline BPAg1 (BP230) & Hemidesmosome (intracellular) \\
\hline Integrin subunits a6//44 & Hemidesmosome (transmembrane) \\
\hline Laminin-5 (laminin-332/epiligrin, a-3, $\beta-3, \gamma-2$ chains) & Lower lamina lucida \\
\hline Laminin-6 & Lower lamina lucida \\
\hline Type VII collagen & Lamina densa/Sub-lamina densa \\
\hline
\end{tabular}


Table 2

Presentations of MMP

\begin{tabular}{|c|c|}
\hline Sites involved & Presentations and potential complications \\
\hline Skin & $\begin{array}{l}\text { In } 25-30 \% \text { of patients }{ }^{19} \\
\text { Localized erythematous plaque near affected mucosal surfaces, generalized bullous eruption particularly on the head and } \\
\text { upper body, or vegetating lesions occasionally } 102,103 \\
\text { Scarring, cicatricial alopecia on the scalp }{ }^{104,105}\end{array}$ \\
\hline Oral cavity & $\begin{array}{l}\text { In over } 85 \% \text { of patients } \\
\text { Desquamative gingivitis, erosions, ulceration (Fig. 1) } \\
\text { Pseudomembrane } \\
\text { Vesicles rarely seen (Fig. 2), bleeding } \\
\text { Pain and inability to eat certain types of food } \\
\text { Self-limiting mostly } \\
\text { Mild scarring or atrophy, intraoral adhesion, loss of teeth rarely }\end{array}$ \\
\hline Eye & $\begin{array}{l}\text { The second most common site (in } 65 \% \text { of patients) }{ }^{106} \\
\text { Nonspecific conjunctivitis } \\
\text { Erosions, corneal damage } \\
\text { Photophobia and photosensitivity, dryness } \\
\text { Progressive process leading to scarring } \\
\text { Symblepharon (Fig. 4), ankyloblepharon, trichiasis, entropion } \\
\text { Blindness in close to } 15 \% \text { of patients }\end{array}$ \\
\hline Nose & $\begin{array}{l}\text { In } 20-40 \% \text { of patients } \\
\text { Discharge, erosion, excessive crust } \\
\text { Scarring } \\
\text { Breathing difficulty }\end{array}$ \\
\hline Larynx & $\begin{array}{l}\text { In } 5-15 \% \text { of patients } \\
\text { Sore throat, hoarseness } \\
\text { Scarring, stenosis of airway } \\
\text { Breathing difficulty }\end{array}$ \\
\hline Esophagus & $\begin{array}{l}\text { In } 5-15 \% \text { of patients } \\
\text { Dysphagia, odynophagia, esophageal reflux } \\
\text { Stricture formation } \\
\text { Disability in eating } \\
\text { Death }\end{array}$ \\
\hline Anogenital area & $\begin{array}{l}\text { In } 20 \% \text { of patients } \\
\text { Erosion and ulceration } \\
\text { Bleeding } \\
\text { Pain } \\
\text { Dysuria }\end{array}$ \\
\hline
\end{tabular}


Sites involved Presentations and potential complications Sexual dysfunction 
Table 3

Diagnostic criteria for MMP

\begin{tabular}{|ll|}
\hline Clinical features & $\begin{array}{l}\text { Chronic, inflammatory, blistering disease Predominantly affecting any or all mucous membranes, with or } \\
\text { without skin involvement, and with or without identifiable scarring }\end{array}$ \\
\hline Direct immunofluorescence & Continuous deposits of IgG, IgA and/or C3 in the epithelial BMZ \\
\hline
\end{tabular}


Table 4

Features of MMP subgroups

\begin{tabular}{|lll|}
\hline Subgroup & Autoantigens & Clinical features \\
\hline Pure ocular involvement & Integrin $\beta 4$ subunit & High-risk \\
\hline Pure oral involvement & Integrin a6 subunit & Low-risk \\
\hline Mucosal and skin involvement & BP180 & Heterogeneous outcome \\
\hline Multiple mucosal involvement & Heterogenous autoantigens & Heterogeneous outcome \\
\hline
\end{tabular}




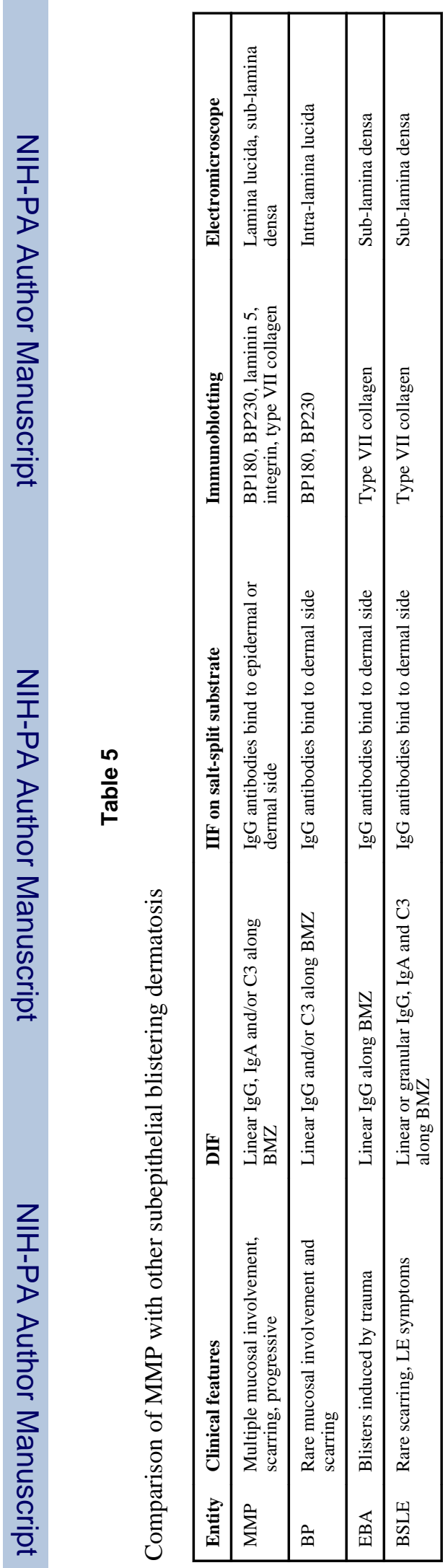

Dent Clin North Am. Author manuscript; available in PMC 2014 October 01. 


\title{
Table 6
}

Systemic medications

\author{
Low-risk patients \\ Tetracycline (1500-2000 mg/day) or minocycline (50-100 mg/day) \\ Dapsone: Initial dose of 50mg/day, increase by $25 \mathrm{mg}$ every 7 days to $100-200 \mathrm{mg} / \mathrm{day}$ as needed and tolerated \\ Corticosteroids: Prednisone $0.5-1.0 \mathrm{mg} / \mathrm{kg} / \mathrm{day}$ \\ Severe disease \\ Corticosteroids: Prednisone $1-2 \mathrm{mg} / \mathrm{kg} /$ day; or dexamethasone $100 \mathrm{mg} /$ day for 3 days (pulse therapy); or intravenous pulse therapy at $0.5-$ \\ $1.0 \mathrm{~g}$ for 3 days \\ Mycophenolate mofetil: $35-45 \mathrm{mg} / \mathrm{kg} /$ day \\ Azathioprine: initial dose $1-2 \mathrm{mg} / \mathrm{kg} / \mathrm{day}$; can be raised to $5 \mathrm{mg} / \mathrm{kg} / \mathrm{day}$ \\ Intravenous immunoglobulins: $2 \mathrm{mg} / \mathrm{kg} /$ cycle every 4 weeks \\ Cyclophosphamide: $1-2 \mathrm{mg} / \mathrm{kg} / \mathrm{d}$ for progressive, organ- or life-threatening patients \\ Methotrexate: $12.5-22.5 \mathrm{mg} / \mathrm{wk}$ \\ Cyclosporine: $100-250 \mathrm{mg} /$ day \\ TNFa antagonist (etanercept): 25-50 mg, once or twice a week \\ CD-20 monoclonal antibody (rituximab): $375 \mathrm{mg} / \mathrm{m}^{2}$ in 4-week intervals or $1000 \mathrm{mg} 2$ weeks apart for two treatments total
}

